\title{
Effects of Cat and Dog Interactions on Urban Wildlife Admitted to a Wildlife Center in Wisconsin
}

\author{
Makayla Timm ${ }^{1 *}$ and Nicole M. Kime ${ }^{1}$
}

Small birds and mammals are often injured by dogs and cats. Some of these animals are brought to the wildlife rehabilitation centers. The number of admitted animals varies seasonally, and dogs and cats can have different effects on animals in different life stages. This study looked at 9,696 records of small birds and mammals admitted to a wildlife center in the Upper Midwest (Wisconsin) between 2014 and 2017. Data regarding taxon, species, date of admission, life stage, circumstance of rescue, and outcome were compared between dogs and cats. Data from dog and cat interactions were also compared to other causes for admission. More animals were admitted because of dog interactions than cat interactions. Dog and cat interactions are especially prevalent April through August. The proportion of birds and mammals admitted during the breeding season compared to other seasons was higher for dog and cat interactions than the same proportion for other causes of admission $(p<0.001)$. This is partially because young animals are a target. Fledgling birds were admitted more frequently than adults or hatchlings because of interactions with dogs or cats $(p<0.001)$. Mortality rate was lower for dog and cat interactions than other causes of admission $(p<0.001)$, and was lower following interactions with cats than with dogs $(p<$ 0.001 ). Reducing the number of outdoor cats and watching free-roaming dogs more closely may reduce interactions with wildlife and decrease the need for medical assistance for wildlife because of such interactions.

\section{INTRODUCTION}

Cats are thought to pose a significant threat to the small birds and mammals upon which they prey (Loyd et al., 2013). A systematic review of the mortality of birds and mammals caused by free-roaming cats in the United States estimates that free-ranging domestic cats kill $1.3-4.0$ billion birds and 6.3 - 22.3 billion mammals annually (Loss et al., 2013). Entire populations of birds and other wildlife species are declining or being pushed toward extinction by domestic cats (Carey, 2017). The American Bird Conservancy estimates that only $35 \%$ of cat owners always keep their cats indoors, leaving more than 30 million owned cats free to prey on urban wildlife (Burton and Dobler, 2004). Cats are primarily a threat in the early summer, during birds' vulnerable fledgling stage (Donovan, 2012). Cats also have a high reproductive ability, having up to three litters per year yielding four to six

Address correspondance to:

'Department of Biological Sciences, Edgewood College, 1000 Edgewood College Dr, Madison, WI 53711

*Mtimm426@gmail.com

doi:10.22186/jyi.38.6.61-66

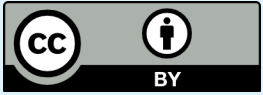

Except where otherwise noted, this work is licensed under $h$ ttps://creativecom mons.org/licenses/by/4.0 kittens per litter (Burton and Dobler, 2004), each of which can be a threat to wildlife.

There has not been much research on how domestic dogs in the United States affect wild animals. Dogs can cause physical injury, nest destruction, and death to wildlife animals (Forrest and Cassady, 2006). They can also harass or chase endemic species, which results in increased stress and energetically costly behavior among native wildlife (Lenth, 2008). A survey conducted in 2016 by the American Pet Products Association estimates that there are about $89,000,000$ domestic dogs in the United States. Some domestic dogs are trained to facilitate hunting, protect property, or reduce human-wildlife conflicts by protecting livestock from people or predators (Melson, 2009).

In Wisconsin, 26 counties have wildlife rehabilitation centers or licensed rehabilitators that care for injured or orphaned urban wild animals with the intent to release them back into the wild (Wisconsin DNR). The Dane County Humane Society's Wildlife Center (DCHS Wildlife Center) treats over 3,800 animals per year that are sick, injured, or orphaned with the goal of releasing healthy animals back into their natural habitats (Dane County Humane Society, 2020). Although data on intakes to wildlife rehabilitation centers cannot be used to estimate the total number of birds and mammals injured by domestic pets or to know how dogs and cats affect bird and mammal populations, they may provide insight into the species and life stages that are most affected. Reviewing existing data from DCHS Wildlife Center can also help other rehabilitation centers in Wisconsin understand when animals will be admitted due to dog and cat interactions, the life stages of animals admitted, and the mortality and release rates of animals. 
The objective of this study was to review data regarding the impact of dog and cat interactions on urban wildlife admitted to DCHS Wildlife Center. Data from 2014 to 2017 were extracted from a commercial database (WILD-One, Wildlife Center of Virginia). Four main factors were explored. The number of small mammals and birds admitted to DCHS Wildlife Center because of a dog interaction was compared to the number of admissions following a cat interaction. The hypothesis was that more animals are brought in because of dog interactions than because of cat interactions because people are more often with their dogs when they are outside, either taking them for a walk or in their backyard. Second, the seasonal distribution of intakes due to interactions with dogs or cats was described. The hypothesis was that animals injured by a cat or dog are admitted primarily during breeding season in Wisconsin (April - August). Third, the number of admissions following dog or cat interactions was compared across life stages of birds. The hypothesis was that fledgling birds are a target for dogs and/or cats. Finally, the outcome of injuries to mammals was compared to those of birds. The hypothesis was that mortality of wildlife admitted because of cats will be greater than the mortality due to dogs because cats are actively hunting.

\section{METHODS}

\section{Animal intake and treatment procedures}

This study was based on animals that were admitted to DCHS Wildlife Center in Madison, Wisconsin between January 2014 and December 20177. DCHS Wildlife Center staff evaluates animals that the community brings in due to suspected illness, injury, or orphanage. If staff determined that an orphaned animal does not need rehabilitation (i.e., it is healthy enough to stay in the wild), they advise the community member not to step in. It is illegal for a rehabilitator to take a healthy non-orphaned wild animal into their care. Animals that are not admitted are not entered into a database.

Upon admission, licensed staff members at DCHS Wildlife Center perform physical examinations to determine the animal's injury (e.g., physical trauma, infectious diseases, emaciation, etc.). If the same patient presents multiple injuries, the most significant injury is recorded first. Not all animals admitted to DCHS Wildlife Center are sick or injured; some are orphaned because their nest was destroyed, or parents did not come back to care for their young. The orphaned patients are still given a physical exam.

Data collected from all admitted wildlife is recorded into the database WILD-One. This includes the patient identification number (patient ID), species, date of admission, admitted life stage, circumstance of rescue, injury, disposition, and disposition date. Life stages for birds and mammals include hatchlings (birds, respectfully, that are still fully reliant on parents and/or still within the nest), fledgling (birds, respectfully, that are not fully dependent but not yet adult size), and adults (fully independent and of adult size and sexual maturity). The disposition of the wildlife animals are recorded as released, euthanized, dead, transferred, or selfreleased. The staff at the DCHS Wildlife Center have developed criteria for euthanasia, implemented after performing a physical exam, in accordance with the law and based on input from sponsoring veterinarians, rehabilitation experts, and federal agencies.

\section{Data analysis}

Data was extracted from WILD-One into Microsoft Excel 2017. Medical records from 13,454 animals, including all animals admitted for rehabilitation between January 2014 and December 2017, were initially reviewed. Reptiles and amphibians were excluded from the subsequent analysis. In addition, data from 3,758 admissions that were not small, terrestrial birds or mammals (raptors, waterfowl, specialty birds, and large mammals) were excluded from analysis. Thus, data from 9,696 small mammals and birds that were admitted for rehabilitation from 2014 through 2017 were analyzed for this study. Of these, 1,494 of the admissions were because of an interaction with a cat or dog. Cat and dog interactions were defined as a record where a wild animal was admitted to DCHS and the rescuer observed or suspected that a domestic animal and the injured wildlife animal were in contact resulting in medical care. Data on birds and mammals admitted for other causes $(8,202)$ were used as a control. In addition to the cause of admission this study analyzed data on the species of bird or mammal, the month they were admitted, their life stage and their outcome.

To test the hypothesis that cat and dog interactions are more prevalent during the summer breeding season (April to August) than other times of the year, the number of intakes from April to August was compared to the number of intakes at other times of the year (September- March). A chi-square analysis was used to compare between seasons the proportion of breeding season intakes due to cat and dog interactions relative to the control group of animals admitted for other reasons.

To investigate differences in the impacts of cat and dog interactions across life stages, only data from birds were used, as life stages are similar in bird species but not the mammals included in this study. To test the hypothesis that fledgling birds are a particular target for cats and dogs, a chi-square analysis was used to compare the proportion of hatchlings, fledglings, and adult birds injured by dogs or cats to the proportion of each life stage the birds admitted for other reasons.

To test the hypothesis that mortality due to cat interactions is greater than mortality due to dog interactions, a chisquare analysis was used to compare the proportion of animals that died following cat interactions to the proportion or animals that died following dog interactions. The null hypothesis was that the mortality rates are equal in dogs and cats. A chi-square analysis was also used to compare mortality rates following dog and cat interactions to mortality rates of animals admitted for other causes. 
Table 1. Small mammal species admitted to DCHS Wildlife Center because of a dog or cat interaction. Eastern cottontails, Virginia opossums, thirteen-lined ground squirrels, common raccoons, and eastern chipmunks that came from a common nest were put together into one nest and counted as one individual. Four animals were not included in the table due to an undermined life stage.

\begin{tabular}{|c|c|c|c|c|c|c|c|c|c|}
\hline MAMMALS & TOTAL & Total Cats & Infant & Juvenile & Adult & Total Dogs & Infant & Juvenile & Adult \\
\hline American badger & 1 & $\mathbf{0}$ & 0 & 0 & 0 & 1 & 0 & 1 & 0 \\
\hline Big brown bat & 23 & 17 & 0 & 0 & 17 & 6 & 0 & 0 & 6 \\
\hline Common raccoon & 5 & $\mathbf{0}$ & 0 & 0 & 0 & 5 & 4 & 0 & 1 \\
\hline Deer mouse & 5 & 4 & 2 & 0 & 2 & 1 & 1 & 0 & 0 \\
\hline Eastern chipmunk & 43 & 30 & 4 & 9 & 15 & 13 & 5 & 4 & 4 \\
\hline Eastern cottontail & 638 & 255 & 95 & 146 & 13 & 383 & 268 & 96 & 18 \\
\hline Eastern fox squirrel & 1 & $\mathbf{0}$ & 0 & 0 & 0 & 1 & 1 & 0 & 0 \\
\hline Eastern gray squirrel & 72 & 17 & 13 & 1 & 2 & 55 & 32 & 13 & 10 \\
\hline Little brown bat & 7 & 6 & 0 & 0 & 6 & 1 & 0 & 0 & 1 \\
\hline Long-tailed weasel & 2 & 2 & 0 & 0 & 2 & $\mathbf{0}$ & 0 & 0 & 0 \\
\hline Meadow vole & 1 & $\mathbf{0}$ & 0 & 0 & 0 & 1 & 0 & 0 & 1 \\
\hline Muskrat & 1 & $\mathbf{0}$ & 0 & 0 & 0 & 1 & 0 & 0 & 1 \\
\hline Northern long-eared bat & 1 & 1 & 0 & 0 & 1 & $\mathbf{0}$ & 0 & 0 & 0 \\
\hline Northern short-tailed shrew & 1 & $\mathbf{0}$ & 0 & 0 & 0 & 1 & 0 & 0 & 1 \\
\hline Red fox & 1 & $\mathbf{0}$ & 0 & 0 & 0 & 1 & 1 & 0 & 0 \\
\hline Silver-haired bat & 1 & 1 & 0 & 0 & 1 & $\mathbf{0}$ & 0 & 0 & 0 \\
\hline Southern flying squirrel & 3 & 2 & 1 & 0 & 1 & 1 & 0 & 0 & 1 \\
\hline Thirteen-lined ground squirrel & 13 & 7 & 1 & 1 & 5 & 6 & 3 & 3 & 0 \\
\hline Virginia opossum & 19 & 3 & 2 & 1 & 0 & 16 & 4 & 6 & 6 \\
\hline White-footed mouse & 1 & 1 & 0 & 0 & 1 & $\mathbf{0}$ & 0 & 0 & 0 \\
\hline Woodchuck & 8 & $\mathbf{0}$ & $\mathbf{0}$ & $\mathbf{0}$ & $\mathbf{0}$ & 8 & $\mathbf{0}$ & 1 & 7 \\
\hline TOTAL & 847 & 346 & 118 & 158 & 66 & 501 & 319 & 124 & 57 \\
\hline
\end{tabular}

\section{RESULTS}

Dog interactions were the third leading cause of small mammal and bird admissions (9.7\% of all admissions) at the DCHS Wildlife Center. Cat interactions were the eighth leading cause of mammal and bird admissions (5.6\%) out of twenty-one other causes of admission.

The number of animals admitted because of cat and dog interactions varied among species (Table 1 and 2). The mammal and bird species that were most frequently admitted because of a cat interaction were the Eastern cottontail rabbit (Sylvilagus striatus, $53 \%$ of animals admitted because of cat interactions), Eastern chipmunk (Tamias striatus, 5\%), American Robin (Turdus migratorius, 6\%) and Mourning Dove (Zenaida macroura, 3\%). The mammal and bird species that were admitted most frequently because of a dog interaction were the Eastern cottontail rabbit (72\% of animals admitted because of dog interactions), Eastern gray squirrel (Sciurus carolinensis, 6\%), American Robin (4.6\%), and Mourning Dove (1.4\%).

Overall, more mammals and birds were admitted because of dog interactions than cat interactions. Dog and cat interactions admitted more mammals than birds. More birds were admitted because of cat interactions than dog inter- actions, but more mammals were admitted because of dog interactions than cat interactions (Figure 1).

Mammals and birds were admitted throughout the year because of cat and dog interactions but most were admitted during their breeding seasons, between April and August (Figure 2). The proportion of animals admitted during the breeding season (compared to other seasons) was higher for dog and cat interactions for animals brought in for other reasons $\left(X_{2}=91.622, d f=1, p<0.001\right)$. There was no discernible difference in the number of animals admitted among the four years of the study (Fig. 2).

Fledgling birds were admitted because of dog and cat interactions more frequently than adults and hatchling birds (Figure 3). The proportion of hatchlings, fledglings, and adult admissions differed between cat and dog interactions and other causes $\left(X_{2}=36.568, d f=2, p<0.001\right)$.

To investigate dog and cat-related mortality rates, animals that were euthanized and animals that died either while in care or before the exam were combined into one category. Animals that were released were placed in a second category. Animals that were transferred or self-released were not included in the analysis. Animals admitted because of cat or dog interactions were less likely to die than animals 
Table 2. Small bird species admitted to DCHS Wildlife Center because of a dog or cat interaction. American Goldfinches, House Finches, and American Robins that came from a common nest were put together into one nest and counted as on individual.

\begin{tabular}{|c|c|c|c|c|c|c|c|c|c|}
\hline SMALL BIRDS & TOTAL & Total Cats & Hatchling & Fledgling & Adult & Total Dogs & Hatchling & Fledgling & Adult \\
\hline American Crow & 1 & $\mathbf{0}$ & 0 & 0 & 0 & 1 & 0 & 1 & 0 \\
\hline American Goldfinch & 23 & 17 & 0 & 0 & 17 & 6 & 0 & 0 & 6 \\
\hline American Robin & 5 & $\mathbf{0}$ & 0 & 0 & 0 & 5 & 4 & 0 & 1 \\
\hline American Tree Sparrow & 5 & 4 & 2 & 0 & 2 & 1 & 1 & 0 & 0 \\
\hline Baltimore Oriole & 43 & 30 & 4 & 9 & 15 & 13 & 5 & 4 & 4 \\
\hline Barn Swallow & 638 & 255 & 95 & 146 & 13 & 383 & 268 & 96 & 18 \\
\hline Black-Capped Chickadee & 1 & $\mathbf{0}$ & 0 & 0 & 0 & 1 & 1 & 0 & 0 \\
\hline Blue Jay & 72 & 17 & 13 & 1 & 2 & 55 & 32 & 13 & 10 \\
\hline Brown Thrasher & 7 & 6 & 0 & 0 & 6 & 1 & 0 & 0 & 1 \\
\hline Brown-Headed Cowbird & 2 & 2 & 0 & 0 & 2 & $\mathbf{0}$ & 0 & 0 & 0 \\
\hline Cedar Waxwing & 1 & $\mathbf{0}$ & 0 & 0 & 0 & 1 & 0 & 0 & 1 \\
\hline Chimney Swift & 1 & $\mathbf{0}$ & 0 & 0 & 0 & 1 & 0 & 0 & 1 \\
\hline Chipping Sparrow & 1 & 1 & 0 & 0 & 1 & 0 & 0 & 0 & 0 \\
\hline Common Grackle & 1 & $\mathbf{0}$ & 0 & 0 & 0 & 1 & 0 & 0 & 1 \\
\hline Dark-Eyed Junco & 1 & 0 & 0 & 0 & 0 & 1 & 1 & 0 & 0 \\
\hline Eastern Bluebird & 1 & 1 & 0 & 0 & 1 & $\mathbf{0}$ & 0 & 0 & 0 \\
\hline Eastern Meadowlark & 3 & 2 & 1 & 0 & 1 & 1 & 0 & 0 & 1 \\
\hline European Starling & 13 & 7 & 1 & 1 & 5 & 6 & 3 & 3 & 0 \\
\hline Fox Sparrow & 19 & 3 & 2 & 1 & 0 & 16 & 4 & 6 & 6 \\
\hline Gray Catbird & 1 & 1 & 0 & 0 & 1 & $\mathbf{0}$ & 0 & 0 & 0 \\
\hline Great Crested Flycatcher & 1 & $\mathbf{0}$ & 0 & 0 & 0 & 1 & 0 & 1 & 0 \\
\hline Hermit Thrush & 1 & 1 & 0 & 0 & 1 & $\mathbf{0}$ & 0 & 0 & 0 \\
\hline House Finch & 19 & 12 & 2 & 2 & 8 & 7 & 1 & 3 & 3 \\
\hline House Sparrow & 23 & 16 & 4 & 4 & 8 & 7 & 1 & 1 & 5 \\
\hline House Wren & 6 & 6 & 1 & 3 & 2 & $\mathbf{0}$ & 0 & 0 & 0 \\
\hline Magnolia Warbler & 1 & 1 & 0 & 0 & 1 & $\mathbf{0}$ & 0 & 0 & 0 \\
\hline Mourning Dove & 33 & 19 & 3 & 8 & 8 & 14 & 3 & 3 & 8 \\
\hline Northern Cardinal & 13 & 11 & 5 & 3 & 3 & 3 & 1 & 2 & 0 \\
\hline Northern Flicker & 2 & $\mathbf{0}$ & 0 & 0 & 0 & 2 & 0 & 2 & 0 \\
\hline Orange-Crowned Warbler & 1 & 1 & 0 & 0 & 1 & $\mathbf{0}$ & 0 & 0 & 0 \\
\hline Red-Bellied Woodpecker & 2 & 1 & 0 & 1 & 0 & 1 & 0 & 1 & 0 \\
\hline Red-Winged Blackbird & 6 & 3 & 0 & 2 & 1 & 3 & 0 & 3 & 0 \\
\hline Rose-Breasted Grosbeak & 2 & 1 & 0 & 0 & 1 & 1 & 0 & 0 & 1 \\
\hline Ruby-Throated Hummingbird & 1 & 1 & 0 & 1 & 0 & $\mathbf{0}$ & 0 & 0 & 0 \\
\hline Song Sparrow & 1 & 1 & 1 & 0 & 0 & $\mathbf{0}$ & 0 & 0 & 0 \\
\hline Swainson's Thrush & 2 & 1 & 0 & 0 & 1 & 1 & 0 & 0 & 1 \\
\hline Swamp Sparrow & 1 & 1 & 0 & 1 & 0 & $\mathbf{0}$ & 0 & 0 & 0 \\
\hline White-Breasted Nuthatch & 4 & 4 & 1 & 0 & 3 & $\mathbf{0}$ & 0 & 0 & 0 \\
\hline White-Throated Sparrow & 1 & 1 & 0 & 0 & 1 & $\mathbf{0}$ & 0 & 0 & 0 \\
\hline Yellow Warbler & 2 & 2 & 0 & 0 & 2 & $\mathbf{0}$ & 0 & 0 & 0 \\
\hline Yellow-Bellied Sapsucker & 1 & 1 & 0 & 0 & 1 & $\mathbf{0}$ & 0 & 0 & 0 \\
\hline Yellow-Rumped Warbler & 1 & 1 & 0 & 0 & 1 & $\mathbf{0}$ & 0 & 0 & 0 \\
\hline TOTAL & 270 & 156 & 30 & 54 & 72 & 118 & 14 & 72 & 32 \\
\hline
\end{tabular}




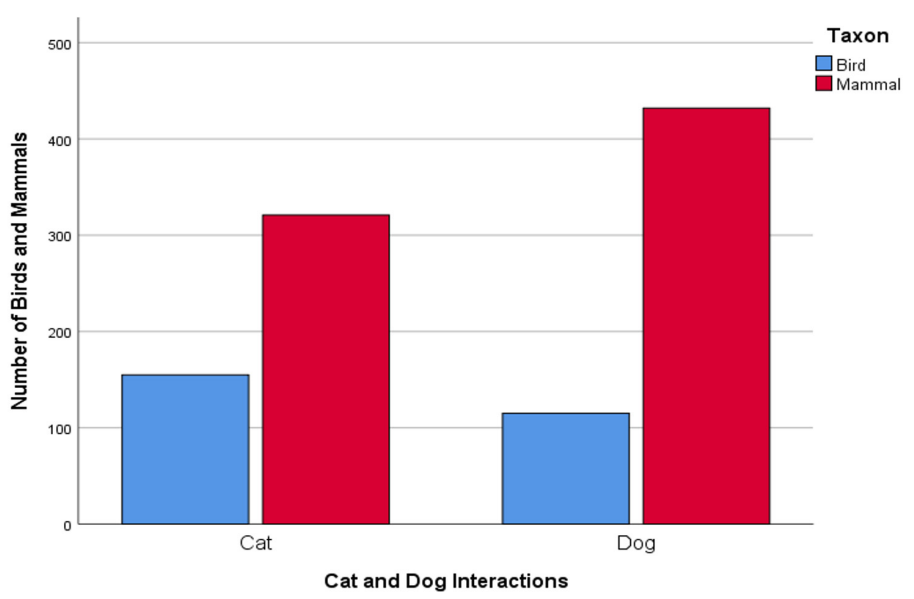

Figure 1. Number of birds and mammals admitted to DCHS Wildlife Center because of a cat or dog interaction in 2014 2017.

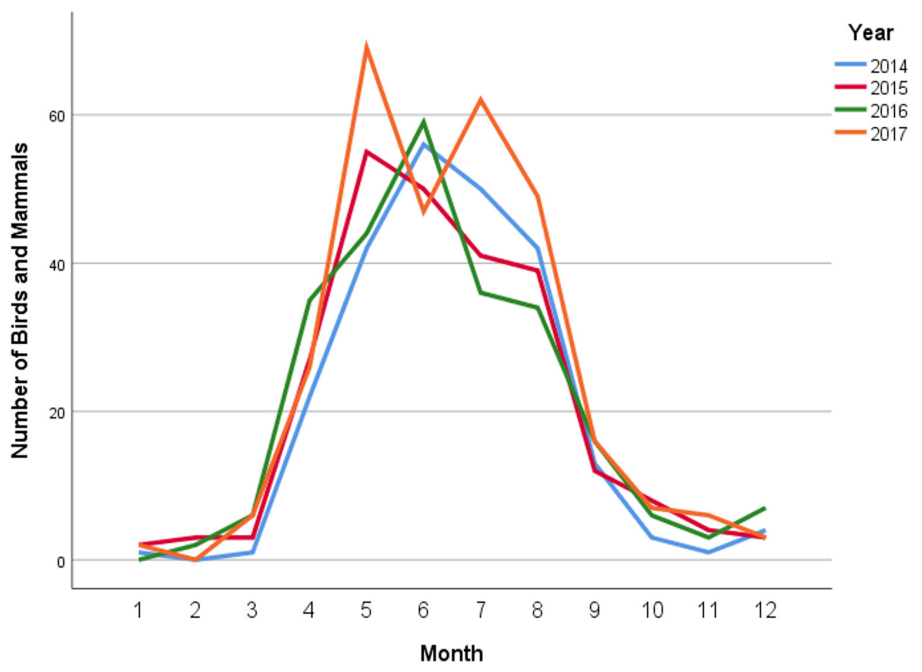

Figure 2. Monthly totals of birds and small mammals admitted to the DCHS wildlife center each year.

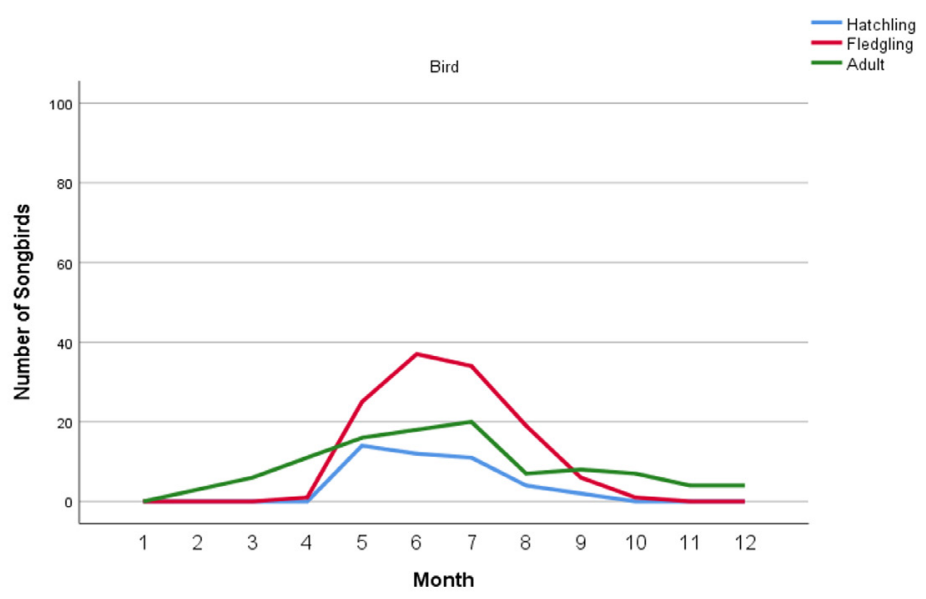

Figure 3. The number of birds by life stage admitted in 20142017 because of a cat or dog interaction per month. admitted for other causes (i.e. nest destruction, moving object, and stationary object) $\left(X_{2}=25.011, d f=1, p<0.001\right)$. When compared to all circumstances of rescue, dog interactions are the second highest reason why birds and mammals were not able to be released and cats were the fourth highest reason out of twenty-one other circumstances of rescue. The most common reason why birds and mammals do not survive is due to orphanage $(16.1 \%)$, where the parents are not available, or the parents rejected their young. Dog interactions had a higher mortality rate than cat interactions $\left(X_{2}=\right.$ $34.273, d f=1, p<0.0001)$.

\section{DISCUSSION}

The purpose of this study was to determine if dog and cat interactions had any impact on small bird and mammal species. Four main factors were addressed. The first analysis compared the number of small mammals and birds admitted to DCHS Wildlife Center because of a dog or cat interaction. The hypothesis was that more animals are brought in because of dog interactions than because of cat interactions. The second analysis described the seasonal distribution of intakes due to interactions with dogs or cats. The hypothesis was that animals injured by a cat or dog are admitted primarily during the breeding season in Wisconsin (April - August). The third analysis compared the life stages of birds that were admitted because of a cat or dog interaction. The hypothesis was that the mortality of wildlife admitted because of cats will be greater than the mortality due to dogs.

Interactions with dogs were the third and interactions with cats were the seventh leading cause of admissions of mammals and birds to the DCHS Wildlife Center between 2014 and 2017. Dogs may have had more admissions due to people walking with their dogs and perhaps having an easier time detecting when these pets encounter wildlife or whether wildlife is injured.

Admissions for cat or dog interactions varied among species. The most common species admitted due to dog or cat interactions were Eastern cottontails, American Robins and Mourning Doves. Birds frequently forage on the ground or at feeders where they are susceptible (Mcruer et al., 2017). Eastern cottontails make nests in backyards which could lead to increased vulnerability to dogs or cats.

The effects of dogs and cats also varied among life stages. In this study, bird fledglings were found to be the most vulnerable to cat and dog interactions, perhaps because they are on the ground and unable to fly well, making them a larger target for cats and dogs. Hatchlings are less likely to be admitted than fledglings because of a cat or dog interaction; this may be because they are usually in their nest in trees. Adult birds may be caught when foraging on the ground, at a bird feeder, or due to having previous injuries (e.g. from a window strike), which can increase their chance of encountering a cat or dog. Adult birds can escape from a predator more easily and are able to defend themselves, 
unlike fledgling birds. Cats are opportunistic predators and their prey selection is correlated with prey availability (Liberg, 1984; Molsher, et al., 1999).

Mammals and birds were admitted because of cat or dog interactions year-round, but fewer admissions occurred during the fall and winter months (September to March). During spring and summer months (April to August), most birds and mammals are in the breeding season, which provides domestic pets opportunities to find baby animals. In addition migratory birds are less present during winter in Wisconsin.

Many animals that are admitted into the DCHS Wildlife Center are either euthanized or die before or during care (1.35\% dead on arrival). The stress of being in captivity, handling , and treatment can inadvertently increase overall wildlife mortality (Mcruer et al., 2016). It can be assumed that if the animal was not admitted and treated for their injuries the mortality rate in the wild would be greater because they are more vulnerable and may die due to their injuries.

The results in this study are significant to understanding when species are being brought in and the life stage of the animals admitted due to dog and cat interactions. Wildlife rehabilitators can use this data to understand the mortality rate, the most common species being brought into a wildlife center, and whether the species may be able to be released.

Domestic dogs and cats are one of the main reasons that small birds and mammals are being admitted into the DCHS Wildlife Center. To make sure that these animals are able to thrive in the wild and not have an interaction with a domestic pet, the number of outdoor cats should be reduced and free-roaming dogs should be watched more closely to decrease the need for medical assistance for wildlife because of these interactions.

Similar wildlife centers can use these data sets to understand how and when dogs and cats injure birds and mammals. In the future, our study could be expanded to include more wildlife centers, to compare data among regions in the United States. A larger study might compare the Upper Midwest to other national regions to determine if there are differences related to climate or culture.

\section{ACKNOWLEDGMENTS}

Thank you to the staff, interns, and volunteers at the DCHS Wildlife Center for treating wildlife and keeping accurate records on the wildlife admitted. Thank you especially to one of the DCHS Wildlife Center staff members, Jacqueline Sandberg for your help and support.

\section{REFERENCES}

Burton, D. L. and Doblar, K. A. (2004). "Morbidity and mortality of urban wildlife in Midwestern United States", International Urban Wildlife Symposium, 171-181.

Forrest, A. and St. Clair, C. C. (2006). "Effects of dog leash laws and habitat type on avian and small mammal communities in urban parks", Urban Ecosystems, 9, 51-66.

Lenth, B., Brennan, M., Knight, R. L. (2008). "The effects of dogs on wildlife communities", Natural Areas Journal, 28, 218-227.
Liberg, O. (1984). "Food habits and prey impact by feral and house-based domestic cats in a rural area in southern Sweden", Journal of Mammalogy, 65(3) 424-432.

Loss, S. R., Will T., Marra, P. P. (2013). "The impact of free-ranging domestic cats on wildlife of the United States", Nature Communications, 4.

Loyd, K. A. T., Hernandez, S. M., Carroll J. P., Abernathy K. J., Marshall G.J. (2013). "Quantifying free-roaming domestic cat predation using animal-borne video cameras", Biological Conservation, 160, 183-189.

Mcruer, D. L., Gray, L. C., Horne, L., Clark, E. E. (2016). "Free-roaming cat interactions with wildlife admitted to a wildlife hospital", The Journal of Wildlife Management, 811, 163, avaliable: doi:10.1002/jwmg.21181.

Melson, M. F., Kahn, P. H., Beck, A., Friedman, B., Roberts, T., Garrett, E. Gill, B. T. (2009). "Children's behavior toward and understanding of robotic and living dogs", Journal of Applied Developmental Psychology, 30(2) 92-102, available: doi: 10.1016/j.appdev.2008.10.011.

Molsher, R. L. (1999). "The ecology of feral cats, Felis catus, in open forest in New South Wales: interactions with food resources and foxes," unpublished.

(2020). Wildlife Center. Dane County Humane Society. https://www. giveshelter.org/wildlife-center. 